\title{
77 Der Mythos von der anstrengungslosen Fettverbrennung
}

\author{
(C) Springer-Verlag GmbH Deutschland, ein Teil von Springer Nature 2018 \\ D. Mathias, Fit und gesund von 1 bis Hundert \\ https://doi.org/10.1007/978-3-662-56307-6_77
}

Sich ausgesprochen langsam bewegen, um möglichst viel Fett abzubauen, ist eine häufig praktizierte Übung von Sporttreibenden in Fitnessstudios. Aber ein solches »Fettverbrennungstraining « macht physiologisch keinen Sinn, weil der Kohlenhydratabbau zeitlich immer der Verstoffwechselung der Fette vorangeht. Für die geringere energetische Flussrate von Fettsäuren ist deren energetisches Äquivalent verantwortlich. Bezogen auf einen Liter Sauerstoff beträgt nämlich die Energieausbeute der Fette trotz ihres mehr als doppelt so hohen Energiegehalts nur 4,7 kcal, die der Kohlenhydrate aber 5,1 kcal ( $\triangleright$ Kap. 5). Dieser bei gleichem Sauerstoffverbrauch knapp $10 \%$ höhere Energiegewinn aus Kohlenhydraten und deren schnellerer Abbauweg begründen die Vorrangstellung der Kohlenhydrate am Energieumsatz.

Dabei ist der Energiestoffwechsel äußerst komplex. An ihm beteiligt sind energiereiche Phosphate wie ATP und Kreatinphosphat, Glucose im Blut, Glycogenspeicher in Muskulatur und Leber, freie Fettsäuren, Triglyceride im Fettgewebe und untergeordnet auch Aminosäuren aus den Eiweißen. Gerade wenig trainierte Personen verwerten aber wegen der energetischen Vorzüge des Kohlenhydratabbaus überwiegend nur ihre Glycogenreserven in der Muskulatur. Erst durch intensiveres Training wird der Stoffwechsel so verbessert, dass der Organismus verstärkt auch seine Fettreserven mobilisieren kann ( $\triangleright$ Kap. 75). Optimal dafür sind körperliche Aktivitäten mit $70 \%$ der maximal möglichen Leistungen.

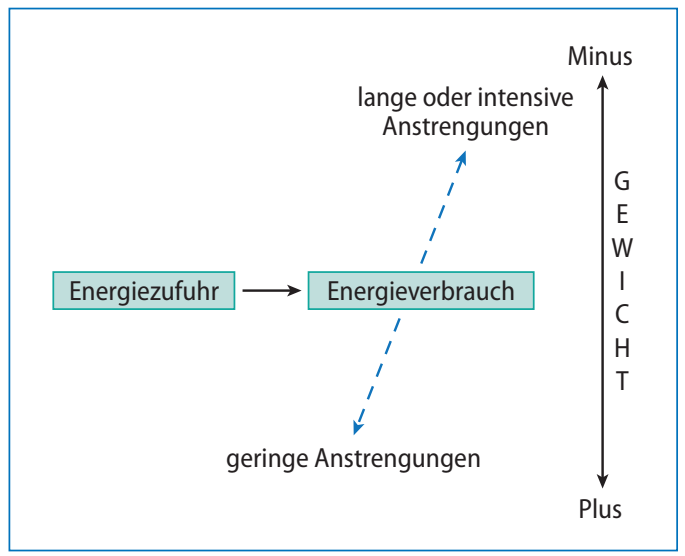

- Abb. 77.1 Wirkungen des Energieumsatzes auf das Gewicht

Speziell unter dem Gesichtspunkt der Gewichtsabnahme gelten ausschließlich die physikalischen Grundgesetze, hier der von Robert Mayer schon 1842 formulierte Energieerhaltungssatz. Danach erreicht man eine Senkung des Gewichts bei gleicher Energiezufuhr lediglich durch Steigerung des Energieverbrauchs.

Je anstrengender sportliche Leistungen sind, umso negativer fällt die Energiebilanz aus und umso höher ist der Gewichtsverlust durch Fettabbau. 